DOI: 10.1515/auseb-2016-0002

\title{
Non-Linearity and Non-Stationarity of Exchange Rate Time Series in Three Central-Eastern European Countries Regarding the CHF Currency in 2014 and 2015
}

\author{
Szilárd MADARAS, ${ }^{1}$ Lehel GYÖRFY ${ }^{2}$ \\ ${ }^{1}$ Department of Economics, Faculty of Economics, Socio-Human Sciences and \\ Engineering, Sapientia Hungarian University of Transylvania, Miercurea Ciuc, \\ e-mail: madaras.szilard@gmail.com \\ ${ }^{2}$ Department of Economics and Business Administration in Hungarian Language, Faculty \\ of Economics and Business Administration, Babeş-Bolyai University, Cluj-Napoca, \\ e-mail: lehelgy@yahoo.co.uk
}

\begin{abstract}
Our paper deals with the consequences of the Swiss National Bank's decision in January 2015 related to the CHF/EUR exchange rate regarding the non-linearity of the RON/CHF, HUF/CHF, and PLN/CHF exchange rate time series. The analysis focuses on the 2014 and 2015 years, respectively, using the daily data of the three national banks. Starting out from the conventional unit root tests (ADF, PP, and KPSS), we complete our analysis with the usage of the Threshold Autoregression model (TAR) recommended by Caner and Hansen (2001), testing the non-stationarity and nonlinearity.
\end{abstract}

Keywords: time series model, unit root tests, threshold unit root test, exchange rates

JEL Classifications: C22 Time-Series Models, F31 Foreign Exchange

\section{Introduction}

Our paper analyses the effects of the CHF/EUR exchange rate shock changes on a few Central-Eastern European state currencies such as RON, HUF, and PLN. Our research focuses on the study of the exchange rates' nature, using a series of unit root tests and a threshold autoregressive (TAR) model for the years 2014 and 2015. We start from the presumption that the consequences of the Swiss National Bank's decision made in January 2015 are reflected properly by the traditional and TAR tests in comparison with the 2014 time series in the case of the analysed currencies. 


\section{Literature review}

The non-stationarity and non-linearity of financial and economic time series is a basic question in literature. The most commonly used unit root tests, ADF (Augmented Dickey-Fuller) and PP (Phillips-Perron), are testing the null hypothesis of non-stationarity. In contrast, the KPSS Lagrange Multiplier test evaluates the null of stationarity (Tsay 2005).

The Threshold Autoregressive model (TAR), a non-linear time series model, was introduced by Tong (1978). A time series $Y_{t}$ is a Self-Exciting Threshold Autoregressive (SETAR) process if it follows the model.

$$
Y_{t}=\phi_{0}^{(j)}+\sum_{i=1}^{(p)} \phi_{0}^{(j)} Y_{t-1}+\mathrm{a}_{t}^{(j)}, \quad r_{j-1} \leq Y_{t-d}<r_{j} \text {, where } j=1, \ldots, k \text { and } d \text { is a }
$$
positive integer. The thresholds are $-\infty=r_{0}<r_{1}<\ldots<r_{k}=\infty$ for each $j,\left\{\mathrm{a}_{t}^{(j)}\right\}$ is a sequence of martingale differences satisfying $E\left(\mathrm{a}_{t}^{(j)} \mid F_{t-1}\right)=0$, $\sup E\left(\left.\mathrm{a}_{t}^{(j)}\right|^{\delta} \mid F_{t-1}\right)<\infty$ a.s for some $\delta>2$ with $F_{t-1}$ the $\sigma$ field generated by $\left\{\mathrm{a}_{t-1}^{(j)} \mid i=1,2, \ldots ; j=1, \ldots, k\right\}$. Such a process partitions the one-dimensional Euclidean space into $k$ regimes and follows a linear AR model in each regime. The overall process $Y_{t}$ is non-linear when there are at least two regimes with different linear models (Tsay 1989).

In our calculations, the threshold variable identification in a two-regime TAR model estimation is based on the unit root test proposed by Canner and Hansen (2001), where the null hypothesis of the threshold effect is tested using the Wald statistic.

The model was widely used in the case of economic time series, studying the unemployment rate, the interest rates, the price evaluation, stock indices, and foreign exchange rates for non-stationary and non-linearity identification (Hansen 2011).

In the two-regime TAR model proposed by Canner and Hansen (2001), the parameters $\rho_{1}$ and $\rho_{2}$ control the stationarity and the null hypothesis of the nonstationary threshold autoregression $\mathrm{H}_{0}: \rho_{1}=\rho_{2}$ (a unit root in both regimes and no threshold effect) is tested using the Wald statistic, with two alternatives:

$H_{1}$ : the first one, as a stationary and ergodic time series based on the one-sided Wald statistic,

$H_{2}$ : the second, as a non-stationary process (a unit root process in one regime, but it will behave like a stationary process in the other regime), with two-sided Wald statistic (Canner Hansen 2001).

In our calculations, we have used a MATLAB code, with a 10,000 bootstrap approximation.

Panos et al. (1997) analysed the equilibrium models of real exchange rate determination in the presence of transaction costs, considering that they imply 
a non-linear adjustment process toward purchasing power parity (PPP). Their results, based on monthly data for the interwar period and annual data spanning two centuries, for GBP, USD, French franc and German mark, reject the linear framework in favour of an exponential smooth transition autoregressive process. They evaluate the linear autoregressive model against the ESTAR alternative. For every exchange rate considered, they find that linearity is clearly rejected.

Taylor et al. (2001), based on Monte Carlo simulations, indicate that when the real exchange rate is non-linearly mean-reverting, standard univariate unit root tests have low power, while multivariate tests have much higher power to reject a false null hypothesis.

In their paper, Imbs et al. (2003) examine the sources of persistent international sectoral price differentials using non-linear modelling; they estimate Threshold Autoregressive (TAR) models at the sectoral level. They confirm the presence of substantial non-linearities in real exchange rate dynamics at the sectoral level.

Kapetanios et al. (2003) propose the ESTAR testing procedure to detect the presence of non-stationarity against non-linear but globally stationary exponential smooth transition autoregressive processes, indicating that this test has better power than the standard Dickey-Fuller test. Their results provide an application to ex post real interest rates and bilateral real exchange rates with the US Dollar from the 11 major OECD countries, and their test proved to be able to reject a unit root in many cases, whereas the linear DF tests fail, providing evidence of nonlinear mean-reversion in both real interest and exchange rates.

Brooks (2001) combines and generalizes a number of recent time series models of daily exchange rate series by using a SETAR model application of the model based on data regarding the daily French franc/Deutschmark exchange rate. He observed that the behaviour of the conditional variance is quite different between the regimes and that models which allow for different regimes can provide superior volatility forecasts compared to those which do not.

Rapach and Wohar (2006) evaluated the out-of-sample forecasting performance of a number of non-linear models of real exchange rate behaviour from the extant literature. They found fairly limited evidence that favours the OT Band-TAR and TPS ESTAR model specifications over simple linear AR benchmark models.

Zhang (2003) extended the tools of time series analysing and forecasting with the usage of the hybrid ARIMA and neural network model.

\section{Data Used}

Our database has been built up in order to contain the official daily exchange rate published by the national banks, separated on the two analysed periods: 03.01.2014 - 31.12.2014 and 05.01.2015 - 24.09.2015 (Figure 1 and 2). 
RON/CHF, PLN/CHF, HUF/CHF, 2014

$-\mathrm{RON} / \mathrm{CHF}$

$-\mathrm{PLN} / \mathrm{CHF}$

$-\mathrm{HUF} / \mathrm{CHF}$

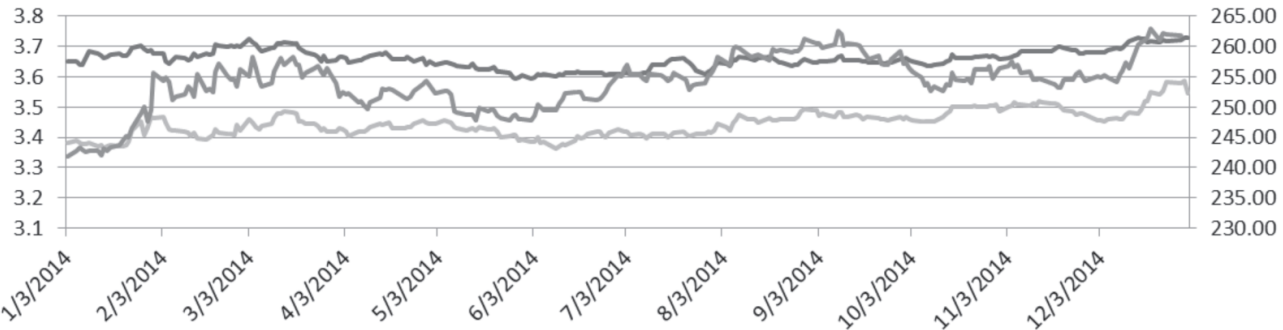

RON/CHF, PLN/CHF, HUF/CHF, 2015 -RON/CHF

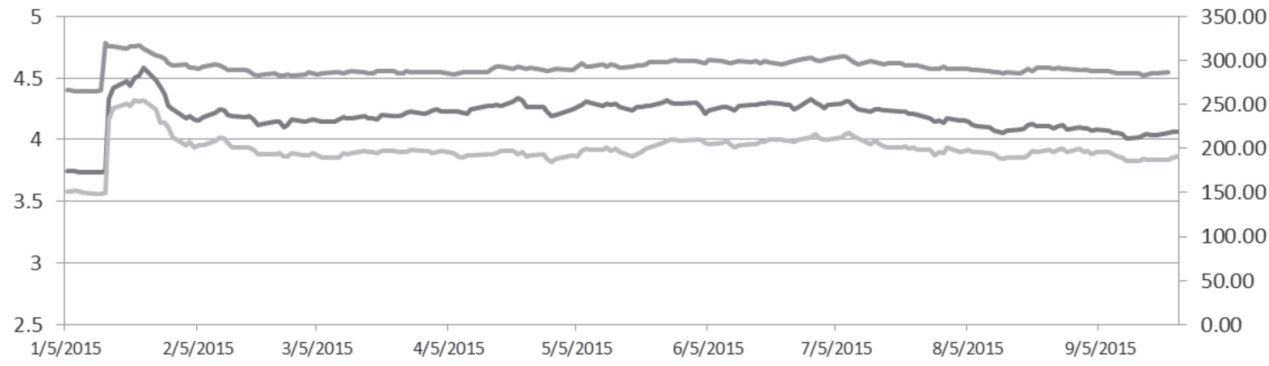

Figure 1 and 2. The RON/CHF, HUF/CHF and PLN/CHF exchange rates in 2014 and 2015

Table 1 contains the descriptive statistics of the analysed exchange rates, which clearly indicates the differences between 2014 and 2015, with higher mean and median values and higher standard deviation for 2015. In 2015, the maximum value for CHF/RON and CHF/PLN rate was registered on 23.01.2015, and for the CHF/HUF on 15.01.2015. 
Table 1. The summary statistics of $R O N / C H F, H U F / C H F$, and PLN/CHF exchange rates in 2014 and 2015

\begin{tabular}{lcccccc}
\hline & \multicolumn{7}{c}{ Exchange rates, Years } \\
\cline { 2 - 7 } & RON/CHF, & RON/CHF, & HUF/CHF, & HUF/CHF, & PLN/CHF, & PLN/CHF, \\
& $\mathbf{2 0 1 4}$ & $\mathbf{2 0 1 5}$ & $\mathbf{2 0 1 4}$ & $\mathbf{2 0 1 5}$ & $\mathbf{2 0 1 4}$ & $\mathbf{2 0 1 5}$ \\
\hline Mean & 3.658735 & 4.191451 & 254.1028 & 291.5105 & 3.445254 & 3.921244 \\
\hline Median & 3.658250 & 4.212100 & 254.5450 & 290.5000 & 3.446300 & 3.906450 \\
\hline Max. & 3.728600 & 4.581700 & 262.8900 & 319.2700 & 3.585900 & 4.322300 \\
\hline Min. & 3.595600 & 3.734600 & 241.9000 & 264.4400 & 3.361400 & 3.562300 \\
\hline Std. Dev. & 0.030877 & 0.137207 & 4.375234 & 9.273040 & 0.042760 & 0.117555 \\
\hline Obs. & 252 & 185 & 250 & 184 & 252 & 186 \\
\hline
\end{tabular}

(Source: Own calculation, www. bnr.ro, www.mnb.hu, www.nbp.pl)

\section{Empirical Results}

In January 15, 2015, the Swiss National Bank (SNB) unexpectedly abandoned its EUR/CHF unofficial floor at €1.20 (Figure 3). Then, there appeared an increasing volatility in all exchange rates (forbes.com).

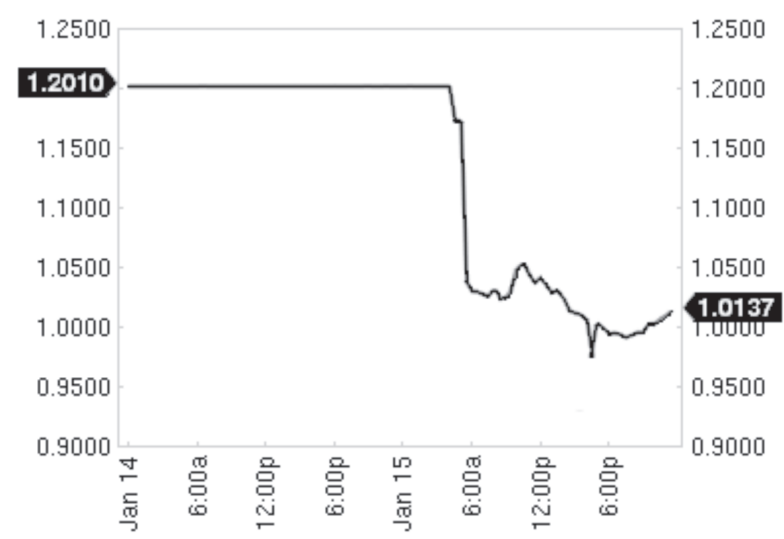

Source: forbes.com

Figure 3. The EUR/CHF exchange rates on $14^{\text {th }}$ and $15^{\text {th }}$ January 2015

First, for the two periods, in order to analyse the nature of the time series, we analysed on the basis of the ADF, P-P, and KPSS tests the null of a unit root, for the three exchange rates. Our results indicate that the ADF test fails to reject the null of non-stationarity for the exchange rate of RON/CHF, HUF/CHF, and PLN/ CHF in 2014, results emphasized also by the PP test in these cases. The results of 
the KPSS test show that only for the HUF/CHF and the PLN/CHF rate and only for the 2014 period can be rejected the null hypothesis at 1\% significance level. In contradiction with these, in 2015, for all three currencies, the ADF and PP tests proved the null of non-stationarity. The results of the KPSS test are similar to the previously mentioned two tests, in 2015. At the same time, as it was expected, the first differenced series were stationary in all three cases, for both analysed periods (Table 2).

Table 2. Univariate unit root tests

\begin{tabular}{|c|c|c|c|c|c|c|}
\hline \multirow{2}{*}{$\begin{array}{c}\text { Exchange } \\
\text { rates, } \\
\text { Years }\end{array}$} & \multicolumn{3}{|c|}{ Levels } & \multicolumn{3}{|c|}{ First Differences } \\
\hline & $\mathrm{ADF}$ & PP & KPSS & ADF & PP & KPSS \\
\hline $\begin{array}{c}\text { RON/CHF, } \\
2014\end{array}$ & $-1.5612(0)$ & $-1.5479(3)$ & $0.3969(12)^{*}$ & $-16.2796(0)^{* * *}$ & $-16.2931(5) * * *$ & $0.1475(6)$ \\
\hline $\begin{array}{c}\text { RON/CHF, } \\
2015\end{array}$ & $-4.0756(0) * * *$ & $-3.8844(5)^{* * *}$ & $0.2441(10)$ & $-10.4951(9)^{* * *}$ & $-11.3499(4) * * *$ & $0.1723(5)$ \\
\hline $\begin{array}{c}\mathrm{HUF} / \mathrm{CHF}, \\
2014\end{array}$ & $-2.6859(1)^{*}$ & $-2.5736(5)^{*}$ & $0.9686(11) * * *$ & $-17.3864(0) * * *$ & $-17.5062(7) * * *$ & $0.1057(9)$ \\
\hline $\begin{array}{c}\mathrm{HUF} / \mathrm{CHF}, \\
2015\end{array}$ & $-3.8841(0) * * *$ & $-3.9562(3)^{* * *}$ & $0.1483(10)$ & $-13.6237(0) * * *$ & $-13.6237(1)^{* * *}$ & $0.1069(1)$ \\
\hline $\begin{array}{c}\text { PLN/CHF, } \\
2014 \\
\end{array}$ & $-1.7393(0)$ & $-2.8304(3)$ & $1.3707(11) * * *$ & $-16.4905(0)^{* * *}$ & $-16.4905(1) * * *$ & $0.0536(4)$ \\
\hline $\begin{array}{c}\text { PLN/CHF, } \\
2015\end{array}$ & $-3.6764(0)^{* * *}$ & $-4.0965(5) * * *$ & $0.0756(9)$ & $-11.5171(0) * * *$ & $-11.5626(4) * * *$ & $0.1010(4)$ \\
\hline
\end{tabular}

(Source: Own calculation, www. bnr.ro, www.mnb.hu, www.nbp.pl)

In the following, based on Caner and Hansen (2001)'s TAR test, we analysed the three exchange rates, for the two periods, indicating where the results are assessable according to the Wald test (Table 3).

Table 3. Threshold test for the exchange rates of $\mathrm{RON} / \mathrm{CHF}, \mathrm{HUF} / \mathrm{CHF}$, and $P L N / C H F$ in 2014 and 2015

\begin{tabular}{lccccc}
\hline $\begin{array}{c}\text { Exchange rates, } \\
\text { Years }\end{array}$ & $\begin{array}{c}\text { Wald } \\
\text { Statistic }\end{array}$ & $\begin{array}{c}\text { Bootstrap } \\
\text { p-value }\end{array}$ & $\begin{array}{c}\text { Optimal delay } \\
\text { parameter } \mathbf{~ m}\end{array}$ & $\begin{array}{c}\text { Threshold } \\
\text { parameter }\end{array}$ & $\begin{array}{c}\text { Number of observations } \\
\text { in Regime 1 and its } \\
\text { percentage }\end{array}$ \\
\hline RON/CHF, 2014 & 44.132661 & 0.094400 & 2 & 0.078508 & $198(82.84 \%)$ \\
\hline RON/CHF, 2015 & 66.364303 & 0.000000 & 6 & 0.033498 & $98(56.97 \%)$ \\
\hline HUF/CHF, 2014 & 37.851095 & 0.536100 & 6 & -0.040369 & $202(85.23 \%)$ \\
\hline HUF/CHF, 2015 & 13.945723 & 0.098800 & 9 & -0.031454 & $145(84.79 \%)$ \\
\hline PLN/CHF, 2014 & 57.362127 & 0.534700 & 9 & -0.020663 & $204(85.35 \%)$ \\
\hline PLN/CHF, 2015 & 38.355001 & 0.914800 & 9 & 0.052968 & $32(18.49 \%)$ \\
\hline
\end{tabular}

(Source: Own calculation, www. bnr.ro, www.mnb.hu, www.nbp.pl)

The optimal delay parameter m value is generally unknown; it was estimated using a 10,000 bootstrap approximation. The results indicate against the null 
hypothesis of the stationary threshold autoregression at least at $10 \%$ in the case of $\mathrm{RON} / \mathrm{CHF}$ in 2014 and $\mathrm{HUF} / \mathrm{CHF}$ in 2015, and at least at 1\% in the case of RON/CHF, 2015 (Table 3).

Caner and Hansen suggested that the one-sided unit root tests are more powerful in the case of the TAR model, and this indicates that the time series are not stationary and ergodic, except for the PLN/CHF in 2015 (Table 4).

Table 4. One-sided unit root tests

\begin{tabular}{|lcccccc|}
\hline & \multicolumn{1}{c}{ R1T } & \multicolumn{3}{c|}{ Bootstrap critical values } \\
\cline { 2 - 7 } & $\begin{array}{c}\text { Optimal delay } \\
\text { parameter m }\end{array}$ & $\begin{array}{c}\text { R1T } \\
\text { statistic }\end{array}$ & $\mathbf{1 0 \%}$ & $\mathbf{5 \%}$ & $\mathbf{1 \%}$ & $\begin{array}{c}\text { Bootstrap } \\
\text { p-value }\end{array}$ \\
\hline RON/CHF, 2014 & 2 & 0.568140 & 9.151486 & 11.283610 & 16.151963 & 0.898700 \\
\hline RON/CHF, 2015 & 6 & 0.716252 & 9.656781 & 11.925852 & 16.262466 & 0.898800 \\
\hline HUF/CHF, 2014 & 6 & 9.408584 & 9.528393 & 11.783826 & 17.856412 & 0.102900 \\
\hline HUF/CHF, 2015 & 9 & 2.570681 & 9.847288 & 11.890980 & 17.001813 & 0.663100 \\
\hline PLN/CHF, 2014 & 9 & 3.631527 & 9.674590 & 11.755744 & 17.407133 & 0.507800 \\
\hline PLN/CHF, 2015 & 9 & 14.626278 & 9.498772 & 11.704289 & 16.613295 & 0.018800 \\
\hline
\end{tabular}

(Source: Own calculation, www. bnr.ro, www.mnb.hu, www.nbp.pl)

A more detailed analysis of the two-regime stationarity could be performed using the partial unit root test proposed by Caner and Hansen (2001).

Table 5a and $\mathbf{5 b}$. The partial unit root results, the $t_{1}^{2}$ statistic (a) and the $t_{2}^{2}$ statistic (b)

\begin{tabular}{lcccccc}
\hline & \multicolumn{1}{c}{$\begin{array}{c}\text { Optimal delay } \\
\text { parameter } \mathbf{m}\end{array}$} & $t_{1}^{2}$ & $\mathbf{1 0} \%$ & $\mathbf{5 \%}$ & $\mathbf{1 \%}$ & $\begin{array}{c}\text { Bootstrap } \\
\text { p-value }\end{array}$ \\
\hline RON/CHF, 2014 & 2 & 0.753751 & 2.424266 & 2.822523 & 3.527715 & 0.593000 \\
\hline RON/CHF, 2015 & 6 & -0.227093 & 2.472208 & 2.862139 & 3.552573 & 0.836900 \\
\hline HUF/CHF, 2014 & 6 & 0.779241 & 2.527003 & 2.893029 & 3.690830 & 0.594000 \\
\hline HUF/CHF, 2015 & 9 & 1.603334 & 2.523655 & 2.921060 & 3.627544 & 0.320400 \\
\hline PLN/CHF, 2014 & 9 & 1.905657 & 2.514161 & 2.883672 & 3.654924 & 0.234300 \\
\hline PLN/CHF, 2015 & 9 & 3.496749 & 2.493994 & 2.894364 & 3.612950 & 0.013400 \\
\hline
\end{tabular}

\begin{tabular}{lcccccc}
\hline & \multicolumn{7}{c}{$\begin{array}{c}\text { Bootstrap critical values } \\
\text { Optimal delay } \\
\text { parameter } \mathbf{m}\end{array}$} & $t_{2}^{2}$ & $\mathbf{1 0} \%$ & $\mathbf{5 \%}$ & $\mathbf{1 \%}$ & $\begin{array}{c}\text { Bootstrap } \\
\text { p-value }\end{array}$ \\
\hline RON/CHF, 2014 & 2 & -0.147282 & 2.467514 & 2.841455 & 3.600820 & 0.846900 \\
\hline RON/CHF, 2015 & 6 & 0.846317 & 2.543103 & 2.973314 & 3.656886 & 0.594100 \\
\hline HUF/CHF, 2014 & 6 & 2.966710 & 2.482669 & 2.896458 & 3.674446 & 0.043400 \\
\hline HUF/CHF, 2015 & 9 & -1.289602 & 2.571305 & 2.934210 & 3.599491 & 0.970800 \\
\hline PLN/CHF, 2014 & 9 & -0.236497 & 2.507206 & 2.909873 & 3.686026 & 0.855000 \\
\hline PLN/CHF, 2015 & 9 & 1.548879 & 2.532245 & 2.903882 & 3.561912 & 0.368100 \\
\hline
\end{tabular}


The results presented above indicate the non-stationarity of the time series in two regimes, with two exceptions: the HUF/CHF in 2014 (Table 5a) and the PLN/ CHF (Table 5b) in 2015, where there is a unit root process in one regime.

\section{Conclusions}

In this paper, we examined the CHF exchange rates' non-linearity and nonstationarity in two periods of times, in 2014 and in 2015, for the currencies of three Central-Eastern European countries. In order to analyse these characteristics of the time series, we used Caner and Hansen (2001)'s TAR test, which is an alternative non-linear model, in comparison with the most commonly used unit root tests.

The ADF and PP unit root tests fail to reject the null of non-stationarity for the exchange rate of RON/CHF, HUF/CHF, and PLN/CHF in 2014. In contrast with that, in 2015, for all three currencies, the ADF and PP tests indicated the null of non-stationarity. The results of the KPSS test are similar to the previously mentioned two tests at $1 \%$ significance level.

The one-sided unit root test results rejected the unit root null hypothesis for RON/CHF, HUF/CHF in 2014 and 2015 and for PLN/CHF in 2014. The results of the partial unit root test suggest a unit root process in one regime in the case of HUF/CHF, 2014 and PLN/CHF, 2015. Taken altogether, our results provide strong support for the RON/CHF in 2014 and 2015 and for the HUF/CHF in 2015 to be characterized as non-linear stationary processes.

\section{Acknowledgements}

We hereby thank to Caner and Hansen, who kindly provided us with their program. Any errors remain our own.

\section{References}

Brooks, C. (2001). A Double-threshold GARCH Model for the French franc/ Deutschmark exchange rate. Journal of Forecasting 20(2): 135-143.

Caner, M.; Hansen, B. E. (2001). Threshold autoregression with a unit root. Econometrica 69(6): 1555-1596.

Imbs, J.; Mumtaz, H.; Ravn, M. O.; Rey, H. (2003). Nonlinearities and real exchange rate dynamics. Journal of the European Economic Association 1(2-3): 639649. MIT Press. 
Kapetanios, G.; Shin, Y.; Snell, A. (2003). Testing for a unit root in the nonlinear STAR framework. Journal of Econometrics 112: 359-379.

Panos, M.; Nobay, A. R.; Peel, D. A. (1997). Transactions costs and nonlinear adjustment in real exchange rates: an empirical investigation. The Journal of Political Economy 105(4): 862-879.

Rapach, D. E.; Wohar, M. E. (2006). The out-of-sample forecasting performance of nonlinear models of real exchange rate behavior. International Journal of Forecasting 22(2): 341-361.

Taylor, M. P.; Peel, D. A.; Sarno, L. (2001) Non-linear mean reversion in real exchange rates: towards a solution to the purchasing power parity puzzles. Centre for Economic Policy Research, Discussion Paper No. 2658, January.

Tsay, R. S. (1989). Testing and modeling threshold autoregressive processes. Journal of the American Statistical Association 84(405): 231-240.

Tsay, R. S. (2005). Analysis of Financial Time Series. New Jersey: John Wiley \& Sons, Inc.

Zhang, G. P. (2003). Time series forecasting using a hybrid ARIMA and neural network model. Neurocomputing 50: 159-175. Elsevier.

\section{Internet Sources}

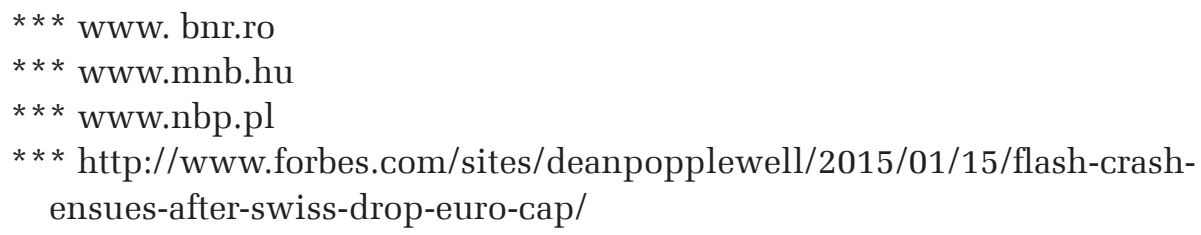

